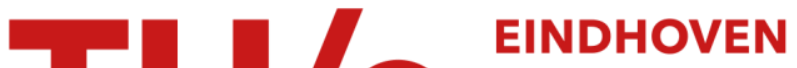 UNIVERSITY OF TECHNOLOGY
}

\section{Sinusoidal behavior of a dipole magnetization for position sensing applications}

\section{Citation for published version (APA):}

Paulides, J. J. H., Lomonova, E. A., Vandenput, A. J. A., \& Zaaijer, E. H. (2006). Sinusoidal behavior of a dipole magnetization for position sensing applications. IEEE Transactions on Magnetics, 42(10), 3294-3296.

https://doi.org/10.1109/TMAG.2006.879764

DOI:

10.1109/TMAG.2006.879764

Document status and date:

Published: 01/01/2006

\section{Document Version:}

Publisher's PDF, also known as Version of Record (includes final page, issue and volume numbers)

\section{Please check the document version of this publication:}

- A submitted manuscript is the version of the article upon submission and before peer-review. There can be important differences between the submitted version and the official published version of record. People interested in the research are advised to contact the author for the final version of the publication, or visit the $\mathrm{DOI}$ to the publisher's website.

- The final author version and the galley proof are versions of the publication after peer review.

- The final published version features the final layout of the paper including the volume, issue and page numbers.

Link to publication

\section{General rights}

Copyright and moral rights for the publications made accessible in the public portal are retained by the authors and/or other copyright owners and it is a condition of accessing publications that users recognise and abide by the legal requirements associated with these rights.

- Users may download and print one copy of any publication from the public portal for the purpose of private study or research.

- You may not further distribute the material or use it for any profit-making activity or commercial gain

- You may freely distribute the URL identifying the publication in the public portal.

If the publication is distributed under the terms of Article 25fa of the Dutch Copyright Act, indicated by the "Taverne" license above, please follow below link for the End User Agreement:

www.tue.nl/taverne

Take down policy

If you believe that this document breaches copyright please contact us at:

openaccess@tue.nl

providing details and we will investigate your claim. 


\title{
Sinusoidal Behavior of a Dipole Magnetization for Position Sensing Applications
}

\author{
Johannes J. H. Paulides ${ }^{1}$, Elena A. Lomonova ${ }^{1}$, Andre J. A. Vandenput ${ }^{1}$, and Erik H. Zaaijer ${ }^{2}$ \\ ${ }^{1}$ Electromechanics and Power Electronics Group, Department of Electrical Engineering, \\ Eindhoven University of Technology, 5600 MB Eindhoven, The Netherlands \\ ${ }^{2}$ SKF Engineering and Research Centre B.V., TDC Mechatronics, 3439 MT Nieuwegein, The Netherlands
}

\begin{abstract}
Position sensing is needed in a large variety of applications, where more specifically Hall-effect position sensors, due to their simplicity and versatility, are elegant solutions. This paper describes a reverse engineering approach to investigate the mismatch in measured Hall-effect voltage of a dipole permanent magnet ring. Using several magnetization patterns, the position signal is reproduced, and it is concluded that by substitution of these patterns, the measured voltage can be recreated.
\end{abstract}

Index Terms-Permanent magnets (PMs), position measurement, transducers.

\section{INTRODUCTION}

$\mathbf{M}$ AGNETIC contactless position sensing is used in many applications, particularly environments in which the sensor is subjected to vibrations, temperature variations, or high levels of humidity. Hall-effect position sensors are elegant solutions to many application requirements by virtue of their simplicity and versatility. However, their maximum operating temperature is limited to $\sim 175{ }^{\circ} \mathrm{C}$, while the distance from the sensor to the magnet surface is usually limited to no greater than $\sim 2.5 \mathrm{~mm}$. Furthermore, it has been demonstrated in [1] that these devices can be sensitive to external air pressures acting on the sensor package.

The applicability of these sensors to angular transducers was already showed by [2]. They emphasized that, although various other sources of errors exist, considerable attention is required to errors due to distortions in the magnetic circuit and temperature effects. In [3], a more geometrical optimization of the permanent magnet (PM)-ring shape and material volume is presented to accommodate both a linear (triangular) or sinusoidal position signal.

All magnetic position applications depend on the applicability of ideal magnetized PM material. This paper illustrates measured signals that exhibit significant position signal distortions. This paper proposes to use these measured signals as a reference, to investigate possible causes for the errors in the position signal.

\section{Magnetic Position Sensing}

Magnetic position sensing system of the type considered in this paper measures the open-circuit magnetic field produced by either a diametrical, or a multipole magnetized permanent magnetic ring using either a single Hall sensor or a pair of sensors.

A typical arrangement of such as system, in this case with a diametrically magnetized ring, commonly fixed to the rotor

Digital Object Identifier 10.1109/TMAG.2006.879764

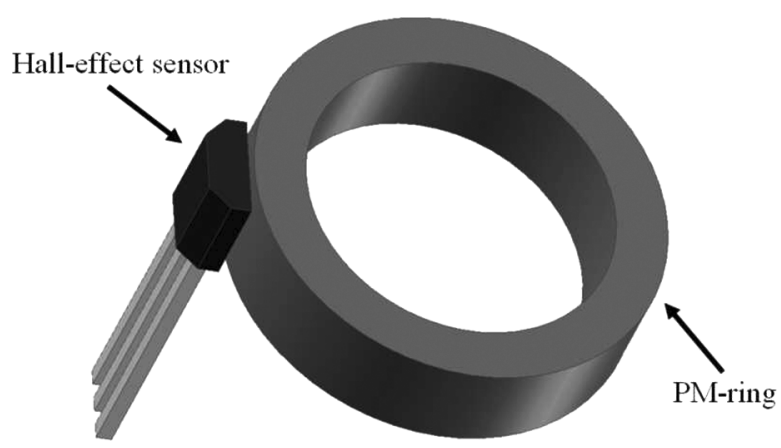

Fig. 1. Schematic of position sensor.

shaft, and a single Hall sensor is shown in Fig. 1. The radial component of magnetic flux density at a given distance from the surface of an ideal parallel magnetized ring varies sinusoidally around the periphery of the magnet ring, with the peak magnitude being determined by the dimensions of the ring and the distance from the sensing element to the magnet surface. Any deviation from an ideal parallel magnetization is likely to result in a nonsinusoidal Hall voltage.

Many systems are reliant on achieving ideal sinusoidal Hall output voltage in order to infer absolute position within one revolution. The presence of harmonics, particularly if they result in erroneous zero-crossings with one revolution, can be problematic.

Practical sensor designs often exhibit part-to-part deviations, in which nominally identical magnet rings produce varying degree of distortion in Hall voltage output. The source of such errors is investigated by means of reverse engineering, i.e., predicting possible geometrical variation in the placement of the Hall-effect and/or misalignments in the magnetization pattern of the dipole PM-ring.

It needs to be noted that the most appropriate way to research this problem is using forward engineering. However, as in many applications, it was not possible to investigate the source, more specifically deficiencies, i.e., inhomogeneties, in the permanent magnet material or misalignments due to the magnetization process. 


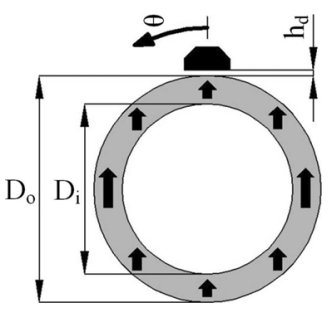

Fig. 2. Cross-section of measurement setup with ideal dipole magnetization pattern.

TABLE I

POSITION SENSOR DIMENSIONS

\begin{tabular}{lcl}
\hline \hline PM-ring outer diameter & $D_{o}$ & $20 \mathrm{~mm}$ \\
PM-ring inner radius & $D_{i}$ & $15 \mathrm{~mm}$ \\
PM-ring axial length & $L_{p m}$ & $3 \mathrm{~mm}$ \\
Hall sensor distance & $h_{d}$ & $0.5 \mathrm{~mm}$ \\
Measurement speed & $\omega$ & $182 \mathrm{rpm}$ \\
\hline \hline
\end{tabular}

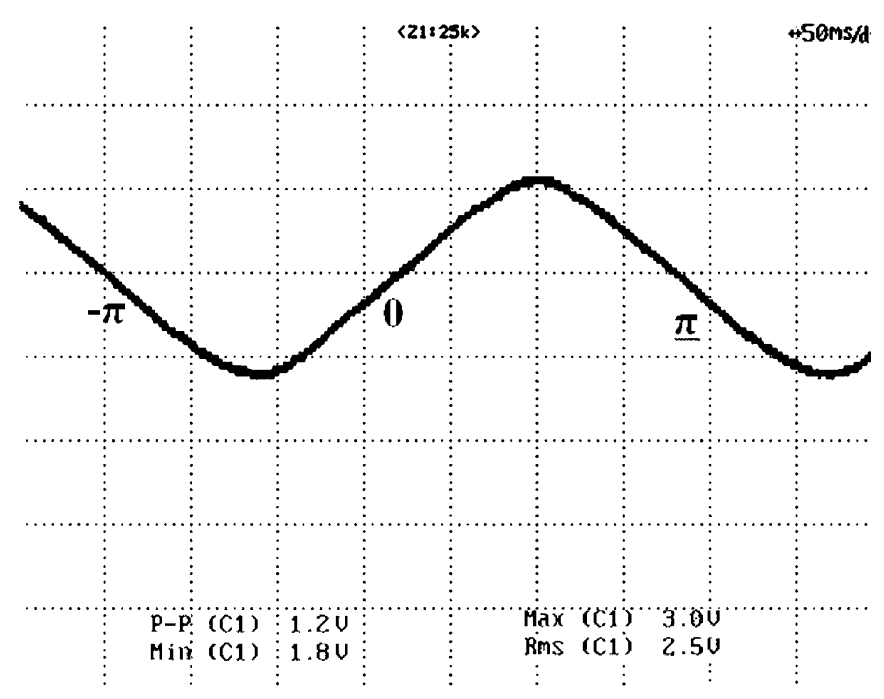

Fig. 3. Measured Hall-sensor output suited for position sensing.

\section{EXPERIMENTAL RESULTS}

A cross-section of the sensor and magnet ring setup employed for obtaining measurement of Hall voltage is shown in Fig. 2, while the key dimensions are listed in Table I. The magnet ring consists of a parallel magnetized anisotropic sintered hard ferrite ring with a nominal room temperature remanence of $0.25 \mathrm{~T}$. The sensors considered in this paper are one-dimensional (1-D) Hall sensors, i.e., they are sensitive only to the component of flux density which is normal to the magnet facing side of the device package (Honeywell SS495A).

A measurement of Hall output voltage from one magnet sample that is deemed adequate for this position sensing is shown in Fig. 3. However, as will be evident, this is by no means a pure sinusoid and in this case contains significant second- and third-order harmonics. Nevertheless, these distortions can be accommodated for by use of an appropriate decoding algorithm. By contrast, Fig. 4 shows a measured Hall voltage from a different magnet ring in which considerable distortion is apparent. Since several different magnet samples proved capable of producing this desired output of Fig. 3, it

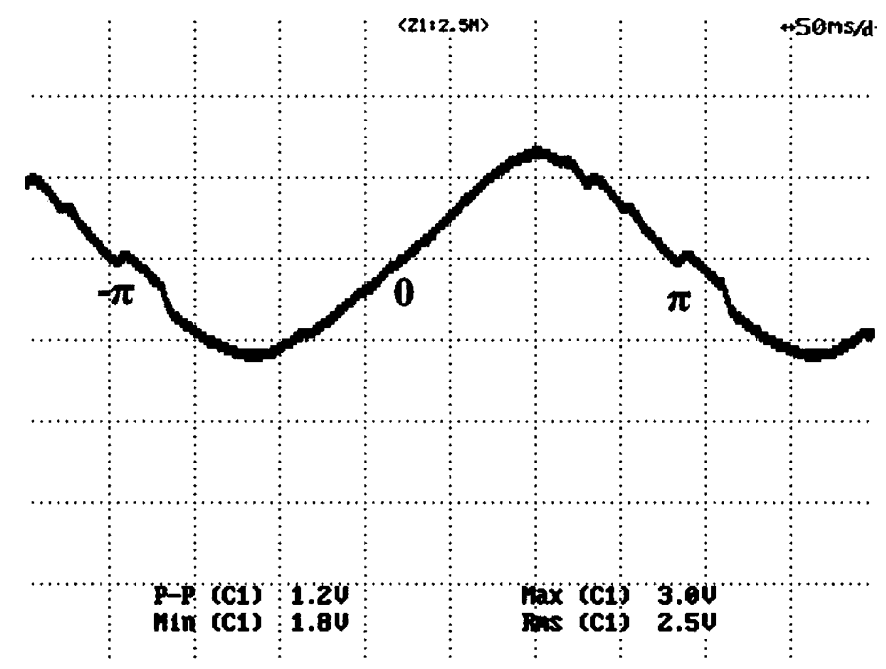

Fig. 4. Measured Hall-sensor output not suited for position sensing.

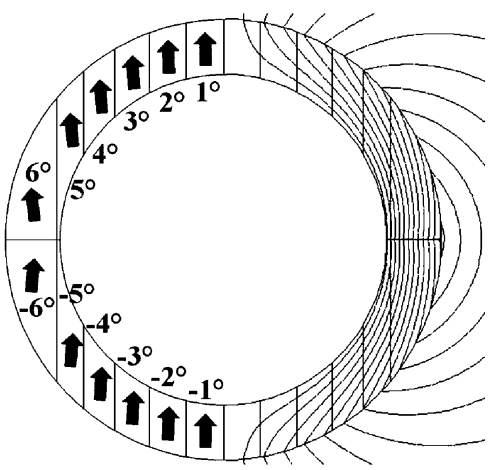

Fig. 5. Schematic of symmetrical magnetization pattern mismatch and resulting equipotential contours.

was deemed to be reasonable to assume that geometrical misalignment of the Hall device relative to the axis of rotation and the magnet surface and vibration could be regarded as having negligible influence. Furthermore, the dimensional tolerances on the magnet outer diameter were extremely small in relation to the separation of the sensing element from the magnet, viz. 0.02 and $0.5 \mathrm{~mm}$, respectively. Hence, it was concluded that the most likely cause of the observed distortion was misalignment in the magnetization pattern in the magnet ring.

\section{Prediction of Magnetization MisalignMents}

Using the ideal dipole magnetization pattern a sinusoidal position signal can be achieved; however, the measured signal (Fig. 3) is not sinusoidal; hence, some "global" misalignments are assumed by offsetting the magnetizations symmetrically and with a gradually increasing deviation, as shown in Fig. 5. The magnetization pattern of Fig. 5 is symmetrical about the 0 and $\pi / 2$ theta-plane, where the segmentation pattern of the PM-ring is such that the global magnetization pattern can be distinguished and the number of segments with varying magnetization angles is minimized.

The influence of this magnetization pattern is investigated by the two-dimensional (2-D) finite-element analysis. Starting from the initial position (Fig. 2), the resulting Hall sensor voltage output is shown in Fig. 6, which shows good agreement 


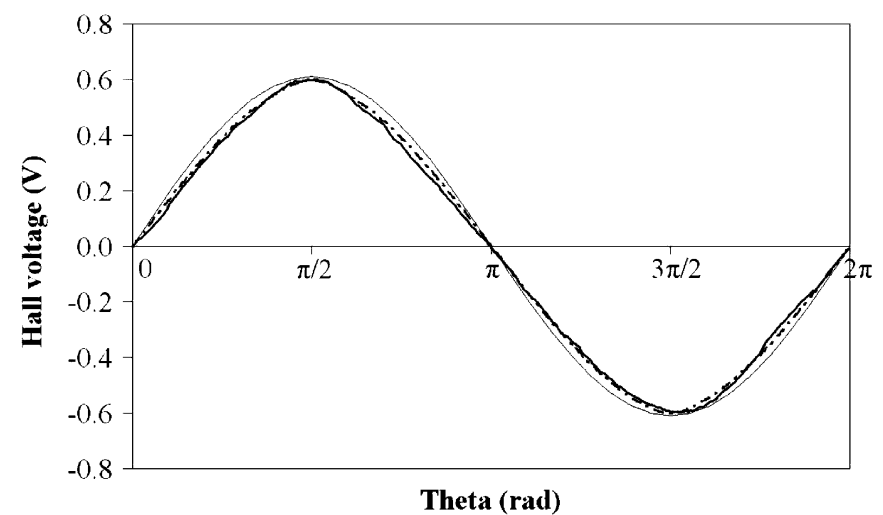

Fig. 6. Measured (solid), predicted (dashed), and ideal sinusoidal (thin solid) Hall-sensor output voltage for the magnetization patterns of Fig. 5.

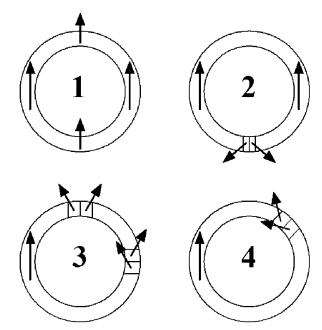

Fig. 7. Possible magnetization pattern mismatches.

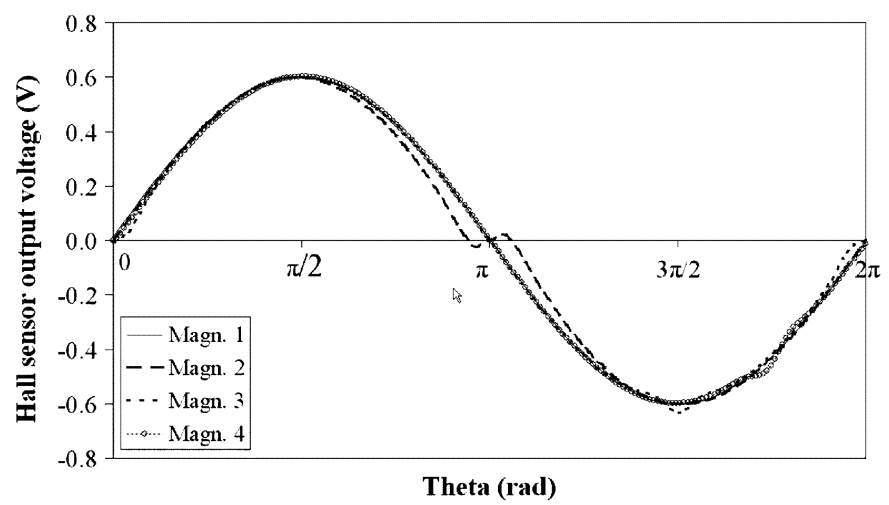

Fig. 8. Hall-sensor output voltage for the magnetization patterns of Fig. 7.

for the measured signal of Fig. 3. However, the distorted measured signal (Fig. 4) clearly indicates that additional localized Hall-sensor output mismatches are still apparent. To look into the possible cause for these localized misalignments, the magnetization angle can be varied. Four particular cases of misalignment, shown in Fig. 7, are investigated. The resulting Hall sensor voltage outputs are illustrated in Fig. 8, which shows that significant deviation of the sinusoidal waveform is apparent when certain segment parts of the PM-ring are misaligned. For example, misalignment such as in magnetization pattern 2 results in multiple zero-crossings, which is the major problem in the position sensing application and is very difficult to be accounted for by the processing algorithm.

\section{CONCLUSION}

In position sensing application, using a hard magnetic ferrite PM-ring has the advantage that it combines the lowest price per energy unit with thermal stability at elevated temperatures. However, nonsinusoidal behavior, as shown by Fig. 3, could result from the PM by misplacement of the magnetizing fixture coils, where a nonuniformity magnetization field can result in the pattern modeled in Fig. 5. The localized deviations, as shown by Fig. 4, are likely to be a consequence of manufacturing errors caused by material density variations (which would affect magnitude of remanent flux density and not magnetization direction), deviations in the angle of orientations, misalignment in magnetizing fixture, etc. Albeit that these localized effects could also result from thermal influences, which may be a contributory factor in this case, which have been reported in hard ferrites [4].

This paper has illustrated possible measurement errors in the Hall-effect voltage (Fig. 3). Using reverse engineering, it is shown that similar characteristics can be reproduced (Fig. 6 and Fig. 8). As a possible cause magnetization mismatches are investigated, which could be the result of the chosen hard magnetic material, manufacturing process, measurement principle, ring design, presence of shaft-material, etc.

\section{ACKNOWLEDGMENT}

This work was supported in part by TDC Mechatronics, SKF Engineering Research Centre, Nieuwegein, The Netherlands.

\section{REFERENCES}

[1] W. J. Flemming, "Overview of automotive sensors," IEEE Sensors J., vol. 1, no. 4, 2001.

[2] R. S. Davidson and R. D. Gourlay, "Applying the hall effect to angular transducers," in Solid State Electron.. N New York: Pergamon, 1966, vol. 9, pp. 471-484.

[3] G. Lemarquand and V. Lemarquand, "Annular magnet position sensor," IEEE Trans. Magn., vol. 26, no. 5, pp. 2041-3303, 1990.

[4] H. D. Glass, B. C. Brown, G. W. Foster, W. B. Fowler, R. Gustafson, G. P. Jackson, J.-F. Ostiguy, and J. T. Volk, "Stability tests of permanent magnets built with strontium ferrite," in Proc. IEEE Particle Accelerator Conf., vol. 3, 1997, pp. 3260-3262.

Manuscript received March 7, 2006 (e-mail: j.j.h.paulides@tue.nl). 